A case for the one-offs: improvisation and innovation within a Copper Age potting community.

Sheila Kohring

Division of Archaeology

Downing Street

University of Cambridge

Cambridge, CB23DZ

(044)1223 333527

sek34@cam.ac.uk

Abstract: Unique objects are often poorly integrated into discussions about the social organization of production or technological processes. Often they are frustratingly interpreted as ritual or prestige objects or they are simply consigned to footnotes in archaeological reports. This does not do them justice and their contextualization may provide greater insight into the social factors involved in production activities. This paper attempts to demonstrate what unique, or one-off, objects can tell us about technological systems and how improvisational technical choices can lead to innovation within society. It focuses on a particular example of pottery production and usage at the Copper Age site of San Blas (Spain) and how two particular vessels on the surface appear to be unique one-off products. This paper shows that one-off objects may in fact be opening the door to innovation through acts of improvisation within existing socially sanctioned production aesthetics and object ideals.

Keywords: Technology, improvisation, innovation, pottery, Copper Age, Iberia

\title{
Acknowledgements
}

A significant thanks goes to V. Hurtado-Pérez, J. Robb, C. Odriozola Lloret and L. García Sanjuan for their long and on-going support in this research and J. Joy and L. García Sanjuan for their preview and comments on earlier drafts. Support has come directly and indirectly through the Universidad de Sevilla, University of Cambridge and EDIA (Empresa de Desenvolvimento e Ingra-estruturas do Alqueva, S.A). I 
would like to thank the Material Culture lab at Cambridge and the CinBA project for presenting on this research and letting me work through these ideas.

\section{A case for the one-offs: improvisation and innovation within a Copper Age potting community.}

\section{Introduction}

Consider the plight of the 'one-off' object or, in this example, the lonely pottery vessel or sherd. At first we explore it with interest and enthusiasm; why is it so unique, are there connections to similar material culture elsewhere, is this an incipient or new form or style? However, as analysis of the assemblage advances, these oneoffs often become problematic. Often typological categories do little justice to these outliers, either ignoring them as statistical aberrations or as footnotes to the wider corpora of analyses. If they do not fit with regional, let alone, local typologies, we may struggle to discuss them in relation to the social interpretation of the wider assemblage. Perhaps, at best, we can look at them as indicative of elite or patronsponsored prestige objects (see Costin 1991; Peregrine 1991) or as ritual or art objects (but see Gell 1996 for a critique), although these descriptors do not always explain those one-offs that are found in household or general contexts. One of the fundamental reasons for our struggle with unique objects may be our approach to complexity which only accounts for the unique or extraordinary once it becomes the norm and then attempts to retroactively seek its origins (Montón-Subías 2010: 2-3). One-offs need to be better understood and their social significance and meaning explored as part of assemblages rather than as unique objects explained in such narrowly defined ways.

In this paper I consider how one-offs within a pottery assemblage can provide meaningful insight into craft production and technological knowledge systems within communities. In particular, I consider how chaîne opératoire analyses allow us to recognize what constitutes socially appropriate objects and the nature of variability within object categories. By exploring variation at specific steps of the chaîne opératoire as they relate to appropriate material categories, I consider the role of improvisation and innovation within its social context to explain how changes become 
established. I explore how improvisation within technological traditions and material products maintains variability, which has the potential to allow innovations to enter and become established, and what their inclusion in analyses can tell us about productive relationships within the wider social context. For this case study, I focus on two particular examples of one-off vessels which were part of a larger late Copper Age assemblage recovered from the site of San Blas (Extremadura, Spain). By looking at these unique vessels in relation to wider patterns of variability in pottery production, I consider how improvisation at certain production stages provided an avenue for the integration of new material categories with new material meanings (such as Bell Beakers) into this community’s material world.

\section{Innovation, improvisation, habitus and technological knowledge}

Humans are continually creative. We adapt and change our habituated practices every day and in every instance to cater to all sorts of physical, environmental and social contexts. As Wagner (1981) points out, creativity is continually emergent as tradition requires both rote repetitive actions as well as innovation since social and cultural circumstances continually change and hence, traditions must adapt (see also de Certeau 1984). This constant creativity occurs, then, as part of a community and within the limits of the knowledge that we hold - it is an intersection, if you will, between individual and community knowledge and practice. As we become increasingly knowledgeable, we become increasingly skilled and habituated in our practices (Mauss 1979; Ingold 2000), affecting the nature of creativity. This does not necessarily mean that as skill grows creativity is streamlined or constrained, as may seem apparent in discussions about craft specialization which focus on standardization (see discussions in Hagstrum 1995), but simply that creativity may occur in different forms. Skill and knowledge structure how creativity takes shape.

What is the relationship, then, between creativity and innovation and, importantly, between innovation and improvisation? This can perhaps be seen in the work of Helen Cordero, a Puebloan potter credited with the invention of new pottery forms in the 1970s. Babcock (1993) explores her creativity as an individual artist by contextualising the long traditions of figurine production and storytelling within Puebloan society. She explores the gendered roles in these activities and situates how 
Helen Cordero first learned traditional figurine production styles and started her own production style reproducing these (typically a figure of a female and child/children) before starting to represent male storytellers. In her analysis, Babcock states that Cordero's decision to represent the storyteller arose from the fact that her own grandfather was a famous storyteller and in the creation of the new genre, Cordero recognised working within the existing tradition but making the figurine firstly male (like storytellers rather than traditional female figurines) and by adding more children than would be expected (ibid 79-81). While Babcock emphasise the gender politics of this invention, I think it is also a clear example of how an individual uses their social and technical knowledge to improvise on the 'accepted' production aesthetic. In essence, creativity can be individual but it is shaped by social context and that context determines whether creativity becomes embedded as innovation. However, the speed by which new objects are accepted, integrated and reproduced by others in society demonstrates how creative improvisation can be translated into innovations with symbolic, political and a whole suite of social implications (see also Hallam and Ingold 2008 for general discussion and case studies)..

Within archaeology, this interest in innovation and invention has been ongoing and essential to fundamental questions about how things change. Evolutionary, behavioural and agency-based models have all provided valuable insight into the discourse with differences most evident in terms of scale of analysis, terminology used and the nature of the agency involved in the creation of innovation. Behavioural approacheshave been one of the most encompassing modes for discussing and modelling innovation, arising as it has from neo-evolutionary foci on questions of origins but certainly moving well beyond this interest to explore the nature of innovation as situated within societies and how they then become established traditions. While evolutionary models have often emphasized the adaptive nature of innovation and focused upon the nature of transmission at the big scale (e.g. Boyd and Richerson 1985; Eerkens and Lipo 2014; Mesoudi 2008; O’Brien et al 2010). Other approaches have attempted to work the middle ground and include smaller scale social decision-making and behaviours in the process. Behavioural approaches have had the most impact in these discussions trying to span scales while still emphasising the relationship between people and things (e.g. Schiffer 1990, 1995, 2005; Schiffer and Skibo 1987; Skibo and Schiffer 2008) 
My approach here uses a more relational approach to emphasise the importance of the material and that is because my questions are not specifically looking at the spread of innovation - be it through cultural transmission or cascading processes - but the role of improvisation within technical systems which might open the door for the ways that innovations can take hold. One mode of framing this issue relates to the use of aesthetics as absolutes or culturally specific and inclusive of practice and context (Morphy 1992; Coote 1994; Gell 1996; Gosden 1999; Pollard 2001). If seen on more of a continuum linked to increased skill and knowledge of the technological process, improvisation can be highlighted to a greater extent. Improvisation in technique and the chaîne opératoire demonstrates knowledge of cultural aesthetics - of those categories which cannot be challenged and those categories which can be challenged. Hence, improvisation reinforces the aesthetics of material categories. By exploring the mode and pattern of improvisation in material culture assemblages we can see how it shapes the direction we can look towards when trying to understand innovation and change. One-off objects - those that don't fit recognised material aesthetic categories can be useful tools to reorient our perspective on change within society. The example below lets us use unique “one-off” objects to explore how the loci for skilled improvisation in the pottery production chaîne opératoire opened the door for new innovations.

\section{San Blas: A typical Copper Age settlement}

The site of San Blas is located on the eastern bank of the Middle Guadiana, which marks the current border between Spain and Portugal (Fig 1). It was excavated by Hurtado Pérez and a team from the Universidad de Sevilla between 2001 and 2003 ahead of the construction of a major hydroelectric dam project which subsequently flooded much of the site (Hurtado 2004: 141). The river provides a significant boundary past and present and shapes the visual character to the settlement which rises from the river to extend up slope towards the piedmont escarpment Sierra de San Blas. The immediate vicinity holds a wealth of history - from a possible Neolithic long barrow to the ruins of a late medieval monastery. The focus of this research, however, is on the Copper Age settlement along the river and slope and, in particular, 
the later end of this prehistoric sequence focusing on the Bell Beaker, or campaniforme, period and Early Bronze Age transition (2400-2000 cal. BC).

The Copper Age site of San Blas is an enclosed settlement with an elaborate entrance at the river, and a smaller enclosure near the top of the walled settlement which separates this area off from the rest of the community (see Hurtado Pérez 2004 for general overview). All the structures excavated within the walled area conform to a similar circular layout and architectural standard. Some of the structures excavated showed evidence of a long history of repeated, even permanent, use throughout the period with multiple phases of post-based construction over time culminating in the establishment of dry-stone walled architecture during the final Campaniforme period. Material culture common at the site included pottery, worked bone tools, ornaments and symbolic objects, clay objects (such as crecientes) and some evidence for early metal-working, although mainly in the form of crucibles.

San Blas is not unique - per se - and there is a recognized trend towards nucleated, enclosed - by walls and/or ditches - settlement in Iberia during the Copper Age (Chapman 1990; Nocete 2001; Hurtado Pérez 2003, 2010; Jorge 2003; Díaz del Río 2004; Márquez Romero \& Jiménez Jáimez 2013), although the diversity of enclosures suggest that different communities had different rationales for construction. Hence, the meanings behind enclosure were equally as diverse (see for example Valera 2012). Reorganization of the social landscape is seen regionally as well and moving up the socio-political scale of analysis, political and economic territories are demarcated in the landscape based on distribution of sites (including fortified sites), material and technologies. In general, the nucleation of settlement and evidence for hierarchical organization of the landscape during the Copper Age evokes questions of new social orders and ideologies. Goods such as metal (Nocete 2006; Costa Caramé et al. 2010; Lull et al 2010), stone such as amphibolite and variscite (Lillios 1997; Valera 2009; Odriozola, Linares-Catela and Hurtado-Pérez 2010), idols and Bell Beakers (see contributions in Rojo-Guerra, Garrido-Pena and García-Martînez de Lagrán 2005) have all been argued to be objects involved in the creation of these new communities and territories. 
The control of prestige-based distribution networks are often used to explain the spread of social and technological innovation which are seen in the archeological record as new material culture and social structures, and metal is often seen as the primary marker of social differentiation during this period - regardless of whether metal is present at sites or not. Bell Beakers, or campaniforme, which are argued to be a wide spread phenomena across central and western Europe during this period of social change are similarly argued to spread - along with ideas of hierarchy and metal

- through these same prestige networks. But, it is often the small-scale view which provides the richness of detail - including the unique and one-offs - that can tell us about the social dynamics at work in periods of change (see Montón-Subías 2010). Within this scale in mind, what can the local pottery assemblage at San Blas, tell us about the way this particular community made sense of the change occurring at this time?

\section{The typical San Blas pottery and the "ubiquitous vessel"}

Unsurprisingly, perhaps at least to the ceramicst, the pottery of San Blas demonstrates both conformity and variability. It is likely pottery was still produced domestically although some producers were more skilled and produced different kinds of pottery vessels (perhaps for specific kinds of practices) than others (see Kohring, Odriozola and Hurtado Pérez 2007). Some pottery may have been traded into the community, particularly between San Blas and the larger, contemporaneous site of La Pijotilla to the north. This may be evident by differences in fabric from some vessels and supported by the close technical and stylistic relationship and interactions between the San Blas, La Pijotilla and other producers in the Middle Guadiana region (Odriozola and Hurtado Pérez 2007; Odriozola et al 2011). The non-Bell Beaker pottery is part of wider regional stylistic traditions and it is this pottery to which we now turn.

A sample of 1058 diagnostic sherds (rims, bases, handles and decorated body pieces) were analysed from eighty-seven different Copper Age contexts relating to three different structures and one intra-mural location as a means to explore technological practices during this period at the site. The sample assemblage included pottery that was related to occupational floors, general fill within structures, specialised activity areas including hearths, silos and concentration areas and general fill within public 
spaces (see Kohring 2007). Methodologically, a generic chaîne opératoire was used to structure the analysis of particular vessel traits in relation to actual technical activities during production. These traits included wall width, vessel form, three characteristics regarding rim shape, surface finish, surface decoration and firing atmosphere (Kohring 2007). The goal of this analytical framework was to explore the latitude of acceptable technological variation within each stage of the production event - to explore which stages required conformity, which were open to individual expression (even innovation) and how these were articulated into a cohesive technological repertoire.

Across the sampled assemblage a certain conventional ideal could be delineated. The “ideal” San Blas vessel was a rounded mid-sized bowl with a wall width of 7-10mm, with an opening of $20-30 \mathrm{~mm}$. It was well smoothed or burnished slightly, with a rounded lip, and was typically black in surface color. This, then, constituted the pottery convention, or ubiquitous vessel aesthetic to which San Blas potters conformed (Fig 2). Based on its presence in all context analyzed, whether domestic or not, the ubiquitous vessel was acceptable for all community activities, for all social occasions and represented a shared conceptual category across different groups (potters, consumers, different kin groups, different statuses) within the community of San Blas. Yet, despite - or, more appropriately, within - convention, great variability also existed.

By looking at the practical application of technological knowledge through the chaîne opératoire variability was quantified based on the comparison between the forms possible at every stage of production and those actually recorded within the assemblage. In general, some stages in the chaîne opératoire obviously have fewer potential options for variation than others, such as choices in firing environment (a stepped continuum between reduced and oxidized firing atmospheres) versus surface decoration (a range of motif styles plus techniques for their production). At every stage of the sequence, however, some potentials were simply not performed (or at least did not make it into the sample assemblage), including at technical stages where there was a noticeable level of variability. Production stages with great variability and the concomitant visual variability in the finished objects - did not necessarily challenge culturally-situated aesthetics, but they opened the door for appropriate 
challenges, or innovations, within the aesthetic. I want to highlight two stages in the technical sequence in this case study to make my point - namely the visual variability found in vessel rims and the investment choices in surface finish, with their effect on concomitant changes in surface decoration, as arenas for improvisation and innovation.

\section{Technological practice and improvisation}

As stated, during the analysis of pottery traits it became obvious that certain steps in the chaîne opératoire were open to greater expression and improvisation. Variability in the chaîne opératoire may have arisen from various routes. At the macro-scale, these may appear as big changes in technical traditions (i.e. innovation), but variation always exists and can provide clues for understanding the macro-scale. For example technical variability may be the result of an individual potter's embodied movements and habitus, from changes in skill within an individual potter's life time, from time and labor investment constraints in any given potting event or through explicit decisions made at the onset of each potting event about the perceived social use of the finished object. Thus variability was and should be viewed as inherent in the process as potters improvised and experimented based on the bricolage and affordances of material, skill and social contingencies of each event. From a technical perspective variability was not, however, completely unstructured and conformed to the aesthetics of production within the community.

Taking a look at the variability in rim formation, there were many potential combinations of shapes and forms materialized in the general pottery assemblage (Figs 3 and 4). Six rim formations styles, however, constituted over 57\% of all styles used across vessels - bowls, plates, storage vessels or beakers. These techniques emphasized the simple rounding or flattening of rims during the production process (Kohring 2007). Within the sample, however, there were 66 different variations in terms of thickening, thinning, rounding, flattening, beveling, everting, inverting and folding. Obviously, embodied technique - or the habituated, tacit and practical knowledge of the individual potter - had a great effect on this variability in the assemblage. Surely unskilled hands at work may result in variable products or misexecuted steps in the chaîne opératoire (see Buddens and Sofaer 2009; Crown 1991; 
Kamp 2001; Sanchez Romero 2008) and some variability in lip and rim formation may be the result of novice or unpracticed potters making vessels. Colomer's (2005) study of pottery variability in Bronze Age communities in southeastern Iberia looked at the contingency of pot-making, pointing out that making vessels for children's burials was done by female family members (mothers) who had highly variable levels of embodied potting skill. Thus, in comparison to the wider Argaric assemblage, this vessel category displayed a higher rate of variability in most stages of production. Variability must consider skill and embodied practice, but contextualizing the variability to assess its structure is an important factor for understanding its nature.

The fact that the majority of techniques conform to a few forms and that the reoccurrence of particular lip and rim attributes in the assemblage suggests that individuals learned ways of making which affected their final result without necessitating deliberate, discursive technical choice every time a vessel was made (Dietler and Herbich 1998; Buddens and Sofaer 2009). This is part of the practical aesthetic as well. As potters learned what was acceptable through discursive commentary and practical use of vessels produced in the community, techniques for production were honed and internalized by the potter and the community users of pottery. The vessels created and contexts of use further constructed what was deemed acceptable to the community in terms of what constituted an appropriate vessel. An appropriate vessel, however, is not necessarily homogenous in all visual and production aspects. In the Copper Age San Blas community variability in rim construction allowed greater individual expression than other traits while still resulting in vessels considered to be generally appropriate by social standards for use in a range of contexts.

We can question whether this kind of variability in lips and rims would have been "seen" and I would argue that from a community perspective it is likely that variability would have been visible and socially important at the local scale even if it was not important as a marker of the vessel category or to wider regional meanings. . Individuals might recognize their own and other's styles and techniques, particular as they gain in skill and knowledge within their community. Recognition of potting communities, or communities of practice, would have been socially important. Previous XRF analysis of a small sample of San Blas pottery demonstrated variations 
in fabric recipes which might have corresponded to household or communitynetworked groups of potters sharing knowledge and practice (Kohring, Odriozola and Hurtado Pérez 2007). Difference, then, might have helped delineate how units within the community organized their production. Once skilled enough, however, potters may have been able to alter their habitus with deliberate intention to see if they could reproduce other styles and forms both within and beyond the San Blas community. Certainly ethnographic and archaeological evidence suggests that potters can and do change, modify and deliberately maintain their production techniques and habitus when integrated into different social contexts or communities of practice, or learning context (Gosselain 2000; Michelaki 2007; Eckert 2008).

So, what is the point? Vessel rims can be variable because embodied practice is situated in individual potter's techniques - it does not necessarily have overt social significance (per Rice 1987: 270). I would argue, however, by looking at the chaîne opératoire as shaping choices, variability is significant as it provides the structural guidelines for the community and allows avenues for change and social relationships to be renegotiated. All technical traditions have pathways for creativity improvisation in response to material and social contingencies - and innovation may take off because certain steps are maintained with great flexibility for experimentation. Individuals learn to improvise throughout their technical practice, but also learn which arenas are more open to experimentation as they become more skilled and adept with the knowledge. This, however, occurs within a social context. Knowing the realms where experimentation can occur is important because the wider community and context play a significant role in the establishment of innovation as an acceptable form of social tradition. For innovations to become established they must be made meaningful through attachment within wider knowledge and aesthetic systems - they must be deemed socially appropriate.

How then do we make sense of things that are unique, individual or "one-offs"? Shifting analytical scale may be appropriate depending on the questions surrounding variability. If we consider the Bell Beaker assemblage at San Blas, we can see how the individual pieces are best contextualized at the regional scale. The Bell Beakers at San Blas are generally bowls or vase forms with incised and infilled geometrically 
organized motifs reminiscent of styles found at the larger site of La Pijotilla northwest of San Blas (a "hotspot" at the end of the Copper Age for exotics, long-distance trade objects and Bell Beakers [see Hurtado Pérez 1984, 1991]). Within the local assemblage, however, these vessels -with their different pastes and surface decoration - stand out in the chaîne opératoire as either external to local pottery improvisation based on chemical and X-Ray diffraction analyses (Odriozola pers comm.) or in terms of diverging chaîne opératoire sequences in temper, paste, firing and surface finish investment other than decoration (Kohring 2007). Furthermore, they made up approximately two percent of the sampled studied and might not have been given proper contextualization if the focus had only been on the local production. Thus, in order to best understand the Bell Beakers at San Blas it is necessary to shift geographic scale to the region rather than the community itself. It is within these contexts that one can begin to discuss innovation as change in material and technical traditions are implemented over a geographical space.

But here I want to address what I think are important localized one-offs in the San Blas assemblage and to contextualize them with reference to existing technological knowledge systems in order to ascertain why some innovations become established and why others remain as one-off improvisations. These should also be considered in relation to social contingencies at the end of the Copper Age and beginning of the Bronze Age. New technologies and technological systems were being introduced across the region, including San Blas, during this period. These include changes in architectural technologies mentioned previously and the presence of small crucibles in some structures and contexts indicates some metalworking at the site. Furthermore, we could even consider the Bell Beakers at San Blas as part of a separate technology here, albeit one made of clay as well, based on the divergent chaine opératoire at the site.

This social change would have had an impact on social organization and relationships and as part of that process of renegotiation existing potting technologies may have been involved in mediating between new technologies and relationships and existing tradition. Within the pottery assemblage, we have vessels that stand out due to investment in production and visual enchantment. For example, there is a small subset of fine walled vessels, which are heavily burnished to provide a shiny visual 
character and slick tactile feel that would have materialized the skill and investment of the potter or user to the community. Use within social contexts would have further imbued these vessels with social meaning. But, two vessels in particular appear as truly unique one-offs in terms of the assemblage and provide interesting case studies for exploring the idea of experimentation and innovation within the San Blas potting community.

Both vessels were recovered from structure J27 located in the enclosed area of the site. Hurtado Pérez (2004) has argued this structure may have been of ritual or symbolic importance due to the presence of exotic bone objects and fine pottery. In fact, there was a large quantity of pottery recovered from this structure in general. The two case study vessels (or fragments that we have) come from the occupational contexts associated with the later Copper Age use of the building. The first is a straight-sided vase or deep bowl in form, with a thickened and flattened rim with a bilobed lip giving the rim a uniquev-shaped profile. The body is also uniquely decorated with stick impressions organized in vaguely linear bands around the top of the body (about four visible) and on the top of the flattened lip we see another band of stick impressions (Fig 5). The second vessel in this case study is an open plate form. The rim of the plate is everted, thick and carefully squared off to create a flat surface on the top and edges of the rim. There is a slight ridge on the bottom of the rim, accentuated by a similarly slight channel between this and the rest of the body of the vessel (Fig 6). The top of the lip is scalloped with seven finger impressions. The surface is burnished to a slick feel and shows considerable investment and time. By comparing these one-offs to the common pottery aesthetics at San Blas, we can explore the structure of improvisations within existing potting technologies as avenues for change.

In terms of formation process, both vessels fall into common conventions within the potting tradition at San Blas. Wall formation for both vessels falls between 7-9mm for the mid-section body construction which is comparable to most non-storage vessels in the assemblage. When looking at labor and temper sorting, there is some variation between the two vessels, with finer temper sorting in the everted plate than the stick-impressed vase, although both fall into clear norms, albeit for different vessel categories, for San Blas pottery. The evert plate appears most similar to 
burnished fine wares with regards to level of temper sorting while the straight-sided vase falls into the general level of tempering practice seen in the majority of domestic pottery (Kohring 2007). Similarly, the firing of both vessels in a fully reduced atmosphere is consistent with the most common firing traditions at San Blas.

Where we see the improvisations in these pottery forms occurring is in the creation of the vessel lip and rim and in the surface finishing - specifically, in terms of lip thickening as a technique and surface decoration. While everted, thickened rims are fairly common and occur across the community, the combination seen on the open plate is unique as the rim is squared off with small ridge running along at the base of the rim. Similarly, the thickening of both the interior and exterior of rim on the stickimpressed vase is a one-off in the sample assemblage. Perhaps the uniqueness of these two vessels is due to sampling error. The pervasiveness of the decoration on both these vessels' rims, however, did make them easily recognizable during analysis. Furthermore, in order to get a perspective of ceramic production and technology across the community, multiple structural contexts as well as contexts from open and public areas were analyzed and no similarly decorated sherds were recovered (see Kohring 2007).

What emerges from the playing around with the production of rims and surface decoration, however, are visually distinct and fundamentally category-vexing finished products. Put into social context, these vessels are recovered from a structure that housed other rare objects on site, such as ceramic fine wares, Bell Beaker vessels and decorated bone and clay objects (Hurtado Pérez 2004: 151). Based on the associated assemblage, then, we can argue that these one-offs were not simply experimentations that did not make sense, but that the improvisation regarding rim and decoration were valued and given community-specific significance. How much did their production challenge or diverge from the rest of the accepted chaine opératoire?

If we compare the techniques and choices being made in the production of the rims of our stick-impressed vase and finger-impressed plate, we can see a very different combination of attributes emerge. In particular, elaborate open formed vessels and flattened rims were chosen, perhaps with the direct intention to accentuate the next stage of decoration. This would immediately have affected the practicing of the 
individual potter's chaîne opératoire as decision-making and time-investment choices were brought to the forefront of the process. Thus, at the intersection of skill and choice in improvisation, experimentation and, in the end, possible innovation becomes more apparent and much more deliberate. The deliberation of choices here suggests the importance of skill in the production of these vessels as they demand working against general inculcated and social practice and technique. In contrast, time investment and care in detail is somewhat more mixed in our two cases and reminds us that improvisation in technique and style does not necessarily mean that the final product's trajectory was to end as an aesthetic idea or unique prestige object. In terms of temper sorting and surface finish, the stick-impressed bowl does not show the adoption of more intense labor investments or strategies. However, investment in both of these stages is seen in the everted-rimmed plate. Surface finish, however, deserves a more thorough examination in both cases however, due to the variation in surface between the assemblage at San Blas and our two case studies.

Twenty percent of the San Blas pottery analyzed in our sample could be classified as decorated in the sense of their surfaces being altered beyond just overall smoothing, polishing or burnishing of the vessel. Of those that retained evidence of decoration, $71 \%$ of motifs constituted simple impressed channels or linear bands around the lip and rim of the vessel. Less than $5 \%$ of the sample exhibited more elaborate decoration. Decorative techniques included painting, punctation and impression, with impressed and comb-impressed motifs being the most common forms of vessel decoration within the sampled assemblage. Impressed motif pottery is found across the region and had in contemporaneous and previous periods been made by shell, fingers, or sharp implements to create well-defined linear designs.

Many of the elaborately decorated vessels at San Blas were classified as Bell Beaker, or campaniforme, based on the style of impressed design and vessel form. This makes our stick-impressed vessel even more unique yet in some ways it is very similar to the campaniforme vessels in the San Blas assemblage. While some campaniforme is of high quality in terms of production techniques and labor investment, following the chaine opératoire of this subset suggested that in actuality, the labor at stages such as temper sorting, surface finish (pre-decoration) and firing were considerably variable leading to the suspicion that it was the act of decoration 
that defined this category of pottery vessel (Kohring 2011). The stick-impressed vessel seems to be following certain of these technical rules for vessel production that are also seen in the San Blas campaniforme. The surface finish is poor on our stickimpressed vessel, perhaps because the decoration is seen to be its defining characteristic. Similarly, while the use of the stick and the kind of decoration appears as a one-off experiment in terms of technique within the assemblage, the fact that it is produced as an impressed design in a linear fashion around the vessel indicates that improvisation was occurring in terms of the kinds of objects used for decoration and the style of producing motifs to create a visually distinct result, but well within existing technical rules and technological logics.

If we look more closely at the finger fluted everted-rim plate, we see a much clearer relationship with existing potting technology (presuming that campaniforme may be following newer or even different networks with further extending linkages) in the local region. In fact, black burnished vessels are common across the local San Blas assemblage and the wider region (Hurtado Pérez pers. comm). In terms of production, the complex shaping of the everted rim vessel indicates a greater labor investment and level of care or skill in its production throughout the chaîne opératoire. The black burnished surface is typical for San Blas vessels in terms of color and surface finish choices, although the burnishing on the plate places it is at the top end of surface finish investment choices. Particular arenas of production choices, however, are being manipulated. Firstly, we see the elaboration, even exaggeration, of the rim area of the vessel to produce that wide flange-like upper edge. While this form and style of vessel is not unique to the existing tradition in the region, it is still fairly uncommon in the San Blas assemblage based on the analysis sample. Furthermore, the choice to produce the rim of the vessel in such a shape provides the canvas for further surface decoration in the form of the finger-fluting around its edge. The finger-fluting decoration has great similarity in terms of the structure of improvisation as with our stick-impressed vessel previously discussed. Impressed techniques are the dominant form of producing decoration in the assemblage and the shallow channels below rims in many cases could have been produced by the use of a finger to demarcate the edge. Thus, the logic of the production is retained while the creation of this fluted edge appears very unique to the assemblage. 
These two uniquely decorated vessels at San Blas pushed the boundaries of acceptability in terms of pottery and their production would have challenged the potter as well. The personal nature of the finger-fluting on the plate or the physicality of jabbing that stick into the clay would have been a very different sensual experience compared to the typical decorative techniques of incision or impressing with tools rather than the bare hand and this closer engagement may have added to their local meaning and significance. These specific techniques were not, however, engaged in with frequency within the potting community although their implementation follows certain existing logics suggesting a mode of improvisation rather than innovation. The possibility of adding improvised, yet acceptable, stylistic motifs to vessels which already showed skill was a visual indicator of both technical and social knowledge and a potential avenue for prestige or status within the community. However, apparently the introduction of innovative motifs and design techniques could not be seamlessly integrated into the existing traditions. Perhaps that is why the chaîne opératoire of the campaniforme vessels followed less specific steps in their production; they were outside the normal aesthetic of the potting community and hence were different. Our stick-impressed vessel with its odd rim and impressed motif may represent how innovation was being integrated into the existing repertoire of production and decoration of pottery within the community through the improvised reworking of certain similar steps in the chaîne opératoire.

\section{Conclusions: Making improvisation innovative}

The production of the two one-off case studies above demonstrates that in certain instances San Blas potters employed their technical skills to push the realms of socially aesthetic vessels through improvisational production of one-off vessels. They were able to do this within socially appropriate ways and within existing technological knowledge systems because they had appropriate sociotechnical knowledge gained from being part of a community of practice. The community of practice, or arena for social learning where people would have engaged with appropriate pots, was multiple in this instance including both the general community as well as their more specific potting community (which may or may not have been insular to the community of San Blas). Once social knowledge of appropriate material, context and production techniques was established in both these communities, these potters not only had the technical ability but the community 
authority to integrate externally situated innovations, such as the campaniforme However, the creation of one-offs like our fluted plate and stick-impressed vase help contextualize how innovations found pathways into existing technology traditions rather than by suddenly appearing as new styles in the region (see also O’Brien and Shennan 2010: 10 for similar evolutionary viewpoint). . By working within the system and in arenas of production in which variability and expression were acceptable: rim formation, time and labor investment and in the application of decoration, these one-offs utilized socio-technic conventions maintained a pathway for new innovations but, in this instance, pushed them to their extreme in order to challenge aesthetic qualities.

Skill and authority may allow greater latitude when the community of practice is small and local, but the use of these final products are just as important, if not moreso, in the establishment of innovation within wider society and here I refer to both material and social innovation such as new social relationships and ideological structures. Gosselain (2008) has pointed out that skilled knowledge in combination with crafting networks and social context plays an important role in establishing change in techniques and values. I would argue that in the San Blas case, the arenas of both production and social action become pivot points for socially appropriate change in techniques and styles.

At San Blas, two such arenas of action can be clearly seen and were spaces that very likely mediated changes in social relationships during the Late Copper Age and Early Bronze Age. Structure J27, in which our two pottery vessels were deposited, was located in the inner enclosure of the settlement and may have had supra-household significance within the community as it had several very rich deposits including a wide variety of exotic material, campaniforme and local finewares (Hurtado Pérez 2004: 152). The presence of our unique one-off vessels along with this rich material assemblage suggests that they were not simply statistical anomalies but integral to the social mediation of new relationships - including those which utilized new and exotic materials such as metal and campaniforme vessels. These associations would have further accentuated the position and status of the potters responsible for these vessels. 
We should also consider structure H22, which was located midway along the slope of the settlement between the river and the inner enclosed area housing J27. This structure also had some exotics and campaniforme, although much less than in J27 (Hurtado Pérez 2004: 151-152). However, in terms of innovation within the potting chaîne opératoire, it appears to have a great degree of technical diversity in its pottery and is more diverse than J27 (Kohring, Odriozla Lloret \& Hurtado Pérez 2007). Hence, while the structure of J27 may have been a venue for playing out new social roles and introducing new sociopolitical relationships during the Copper-Bronze transition, I suspect that H22 was a primary locus for creativity and improvisation in pottery production and provided the foundations for building new materialities and relationships during this period. The two contexts worked together to provide an avenue for innovation in new materials, ideas and technologies. The level of improvisation and the way it was expressed in the community-based pottery assemblage demonstrates how these may have been integrated into existing materialities and technologies.

Thus, by allowing great individual flexibility and openness to variability in different stages of the chaîne opératoire we can consider how improvisation is allowed without necessarily challenging conventions of traditions but while still providing a venue for change and experimentation. Improvisation was introduced into the chaine operatoire at particular stages in the production sequence - it was not unregulated, however, but structured. I argue these stages open to greater improvisation within the technological tradition and potting community became material anchors for the integration of new innovations, such as with the introduction of campaniforme and associated social, material and technological shifts. Exploring the unique one-off object has value in how we understand community, technological practice and change within both. By situating the one-off within its technological systems we may be able to explore the structure of improvisation and the possibility for explaining the situated process by which innovation and social change occur in society.

\section{Bibliography}


Babcock, B. (1993). At home, no womens are storytellers: Ceramic creativity and the politics of discourse in Cochiti Pueblo. In S. Lavie, K. Narayan and R. Rosaldo (Eds.), Creativity/Anthropology (pp. 70-99). Ithaca, NY: Cornell University Press.

Boyd, R. \& Richerson, P. (1985). Culture and Evolutionary Process. Chicago: University of Chicago Press.

Buddens, S. \& Sofaer, J. (2009). Non-discursive knowledge and the construction of identity: Potters, potting and performance at the Bronze Age tell of Százhalombatta, Hungary. Cambridge Archaeological Journal 19(2), 203-220.

Chapman, R. (1990). Emerging complexity: the later prehistory of south-east Spain, Iberia and the West Mediterranean. Cambridge: Cambridge University Press.

Colomer, L. (2005). Cerámica prehistórica y trabajo femenino en El Argar. In M. Sánchez-Romero (Ed.), Arqueología y genero (pp. 177-219). Granada: Universidad de Granada.

Coote, J. (1994). "Marvels of everyday vision” The anthropology of aesthetics and the cattle-keeping Nilotes. In J. Coote, J. and A. Shelton (Eds.), Anthropology, art and aesthetics (pp. 245-273). Oxford: Clarendon Press.

Costa Caramé, M.E., Díaz-Zorita Bonilla, M., García Sanjuán, L. \& Wheatley, D.W. (2010). The Copper Age settlement of Valencina de la Concepción (Seville, Spain): Demography, metallurgy and spatial organization. Trabajos de Prehistoria 67(1), 85117.

Costin, C.L. (1991). Craft specialization: Issues in defining, documenting, and explaining the organization of production. In M.B. Schiffer (Ed.), Archaeological method and theory, volume 3 (pp. 1-56). Tuscon: University of Arizona Press.

Crown, P. (2001). Learning to make pottery in the prehispanic American Southwest. Journal of Anthropological Research 57(4), 451-469. 
De Certeau, M. (1984). The Practice of everyday life (Trans. S. F. Rendall).

Berkeley: University of California Press.

Díaz del Río, P. (2004). Copper Age ditched enclosures in central Iberia. Oxford Journal of Archaeology 23(2), 107-121.

Dietler, M. \& Herbich, I. (1998). Habitus, techniques, style: An integrated approach to the social understanding of material culture and boundaries. In M. Stark (Ed.), The Archaeology of social boundaries (pp. 232-263). Washington, D.C.: Smithsonian Institute Press.

Eerkens, J. and Lipo, C. (2014). A tale of two technologies: Prehistoric diffusion of pottery innovations among hunter-gatherers. Journal of Anthropological Archaeology 35: 23-31.

Eckert, S. (2008). Pottery and Practice: The expression of identity at Pottery Mound and Hummingbird Pueblo. Albuquerque: University of New Mexico Press.

Gell, A. (1996). Vogel's net: Traps as artworks and artworks as traps. Journal of Material Culture 1(1), 15-38.

Gosden, C. (1999). Anthropology and archaeology: a changing relationship. London: Routledge.

Gosselain, O. (2000). Materializing identities: an African perspective. Journal of Archaeological Method and Theory 7(3), 187-217.

Gosselain, O. (2008). Thoughts and adjustments in the potter's backyard. In I. Berg (Ed.), Breaking the mould: challenging the past through pottery (pp. 67-79). BAR International series 1861. Oxford: Archaeopress: Oxford. 
Hagstrum, M. (1995). Creativity and craft: Household pottery traditions in the southwest. In B. Mills and P. Crown (Eds.), Ceramic production in the American Southwest (pp. 281-300). Tuscon, AZ: University of Arizona Press.

Hallam, E. \& Ingold, T. (2008). Creativity and cultural improvisation: an introduction. In E. Hallam and T. Ingold (Eds.), Creativity and Cultural Improvisation (pp. 1-24). ASA Monographs 44. London: Bloomsbury Academic.

Hurtado Pérez, V. (1984). El yacimiento de La Pijotilla (Badajoz). Estudio de relaciones culturales. Tesis doctoral inédita. Universidad de Sevilla

Hurtado Pérez, V. (1991). Informe de las excavaciones de urgencia en La Pijotilla, Campaña 1990. Extremadura Arqueológica 2, 45-68.

Hurtado Pérez, V. (2003). Fosos y fortificaciones entre el Guadiana y Guadalquivir en el III milenio AC: evidencias del registro arqueológico. In S.O. Jorge (Ed.), Recintos murados da Pré-historia recente (pp. 241-268). Coimbra e Porto: Faculdade de Letras da Universidade do Porto.

Hurtado Pérez, V. (2004). El asentamiento fortificado de San Blas (Cheles, Badajoz). III milenio AC. Trabajos de Prehistoria 61(1), 141-155.

Hurtado Pérez, V. (2010). The ditched enclosures of the Middle Guadiana Basin. In A.C. Valera and L.S. Evangelista (Eds), Proceedings of the XV UISPP Congress (Lisbon, September 4-9 2006). Session WS29: The Idea of Enclosure in Recent Iberian Prehistory (pp. 109-122). BAR International Series 2124. Oxford: Archaeopress.

Ingold, T. (2000). The perception of the environment: Essays in livelihood, dwelling and skill. London: Routledge.

Jorge, S.O. (2003). Revisitng some earlier papers on the Late Prehistoric walled enclosures of the Iberian Peninsula. Journal of Iberian Archaeology 5, 89-136. 
Kamp, K. (2001). Prehistoric children working and playing: a southwestern case study in learning ceramics. Journal of Anthropological Research 57(4), 427-450.

Kohring, S. (2007). Pottery technologies and the materialization of society: Late Copper Age community practices in western Spain. Unpublished doctoral thesis, University of Cambridge.

Kohring, S. (2011). Social complexity as a mutli-scalar concept: pottery technologies, 'communities of practice' and the Bell Beaker Phenomenon. Norwegian Archaeological Review 44(2). 145-163.

Kohring, S., Odriozola Lloret, C.\& Hurtado Pérez, V. (2007). Materialising 'complex' social relationships: Technology, production and consumption in a Copper Age community. In S. Kohring, S. and S. Wynne-Jones (Eds), Socialising complexity: structure, integration and power in the Past (pp. 100-117). Oxford: Oxbow Press.

Lillios, K. (1997). Amphibolite tools of the Portuguese Copper Age (3000-2000 B.C.): A geoarchaeological approach to prehistoric economics and symbolism. Geoarchaeology 12(2), 137-163.

Lull, V., Micó, R., Rihuete Herrada, C., \& Risch, R. (2010). Metal and social relations of production in the $3^{\text {rd }}$ and $2^{\text {nd }}$ millennia BCE in the Southeast of the Iberian Peninsula. Trabajos de Prehistoria 67(2), 323-347.

Márquez Romero, J.E. \& Jiménez Jáimez, V. (2013). Monumental ditched enclosures in southern Iberia (fourth-third millennia BC). Antiquity 87(336), 447-460.

Mauss, M. (1979). The Notion of body techniques. In M. Mauss, Sociology and Psychology: Essays by Marcel Mauss (Trans. B. Brewster) (pp. 95-123). London: Routledge and Kegan Paul.

Mesoudi, A. (2008). The experimental study of cultural transmission and its potential for explaining archaeological data. In M. O’Brien (Ed.), Cultural transmission and 
archaeology: Issues and case studies (pp. 91-101). Washington, D.C.: Society for American Archaeology Press.

Michelaki, K. (2007). More than meets the eye: reconsidering variability in Iroquoian ceramics. Canadian Journal of Archaeology 31(2), 143-170.

Montón-Subías, S. (2010). Black swans and archaeological interpretation. Norwegian Archaeological Review 43(1), 1-11.

Morphy, H. (1994). From dull to brilliant: the aesthetics of spiritual power among the Yolngu. In J. Coote and A. Shelton (Eds.), Anthropology, art and aesthetics (pp. 181208). Oxford: Clarendon Press.

Nocete, F. (2001). Tercer milenio antes de nuestra era: relaciones y contradicciones centro/periferia en el Valle del Guadalquivir. Barcelona: Edicions Bellaterra.

Nocete, F. (2006). The first specialised copper industry in the Iberian Peninsula: Cabezo Juré (2900-2200 BC). Antiquity 80, 646-654.

O’Brien, M, Lyman, R., Mesoudi, A. \& VanPool, T. (2010). Cultural traits as units of analysis. Philosophical Transactions of the Royal Society B 365: 3797-3806.

O’Brien, M. and Shennan, S. (2010). Issues in anthropological studies of innovation. In M. O’Brien and S. Shennan (Eds.), Innovation in cultural systems: contributions from evolutionary anthropology (pp. 3-17). Cambridge, MA: The MIT Press.

Odriozola, C., Hunt-Ortiz, M.A., Dias, M.I. \& Hurtado Pérez, V. (2011). Middle Guadiana River Basin (Badajoz, Spain and Alentejo, Portugal) network interactions: insights from the chemical analysis of Bell Beaker pottery and the lead isotope analysis of copper items from the third millennium BC. In I. Terbanti-Memmi (Ed.), Proceedings of the $37^{\text {th }}$ International Symposium on Archaeometry: $12^{\text {th }}-16^{\text {th }}$ May 2008, Siena, Italy (pp. 119-126). Berlin: Springer-Verlag. 
Odriozola, C. \& Hurtado Pérez, V. (2007). The manufacturing process of $3^{\text {rd }}$ millennium BC bone based incrusted pottery decoration from the Middle Guadiana river basin (Badajoz, Spain). Journal of Archaeological Science 34 (11), 1794-1803.

Odriozola Lloret, C. Linares-Catela, J. \& Hurtado Pérez, V. (2010). Variscite source and source analysis: testing assumptions at Pico Centeno (Encinasola, Spain). Journal of Archaeological Science 37, 3146-3157.

Peregrine, P. (1991). Some political aspects of craft specialization. World Archaeology 23(1), 1-11.

Pollard, J. (2001). The aesthetics of depositional practice. World Archaeology 33(2), 315-333.

Rice, P. (1987). Pottery Analysis: A sourcebook. Chicago: University of Chicago Press.

Rojo-Guerra, M.A., Garrido-Pena, R., \& García-Martínez de Lagrán, I. (Eds.) (2005). El Campaniforme en la Península Ibérica y su contexto Europeo. Valladolid: Universidad de Valladolid y Junta de Castilla y León.

Sánchez-Romero, M. (2008). Learning and socialisation in children during the Spanish Bronze Age. In L. Dommasnes and M. Wrigglesworth (Eds.), Children, identity and the past (pp. 112-124). Cambridge: Cambridge Scholars Press.

Schiffer, M. (1990). Technological change in water-storage and cooking pots: some predictions from experiments. In W. Kingery (Ed.), The Changing roles of ceramics in society: 26,000 B.P. to the present (pp. 119-136). Westerville, OH.: The American Ceramic Society.

Schiffer, M. (1995). Technological perspectives on behavioral change. Tuscon, AZ.: University of Arizona Press. 
Schiffer, M. (2005). The devil is in the details: the cascade model of invention processes. American Antiquity 485-502.

Schiffer, M. and Skibo, J. (1987). Theory and experiment in the study of technological change. Current Anthropology 28(5): 595-622.

Skibo, J. and Schiffer, M. (2008). People and things: a behavioural approach to material culture. New York: Springer.

Valera, A.C. (2009). Estratégias de identificação e recursos geológicaos: o anfibolito e a necrópole da Sobreira de Cima, Vidigueira. In A. Bettencourt and L. Bacelar Alves (Eds.), Dos montes, das pedras e das águas: formas de interacção com o espaçco natural da pré-história à actualidad (pp. 25-36). Braga: CITCEM/APEQ.

Valera, A. (2012). Mind the gap. Neolithic and Chalcolithic enclosures of south Portugal. In A. Gibson (Ed.), Enclosing the Neolithic: Recent studies in Britain and Europe (pp. 165.183). BAR International Series 2440. Oxford: Archaeopress.

Wagner, R. (1981). The Invention of culture. Chicago: University of Chicago Press. 
List of Images

Fig 1 Spatial and temporal context of the Copper Age settlement of San Blas, Cheles, Spain.

Fig 2 The 'ubiquitous' San Blas ceramic vessel in the sampled Copper Age assemblage.

Fig 3 The chaîne opératoire of lip variability in the sampled Copper Age San Blas assemblage.

Fig 4 A visual consideration of decorative and lip variability within the sampled Copper Age San Blas assemblage.

Fig 5 Case study 1 - an all-over impressed decorated vessel from the San Blas Copper Age assemblage sample.

Fig 6 Case study 2 - a burnished and finger-fluted open plate form from the San Blas Copper Age assemblage sample. 


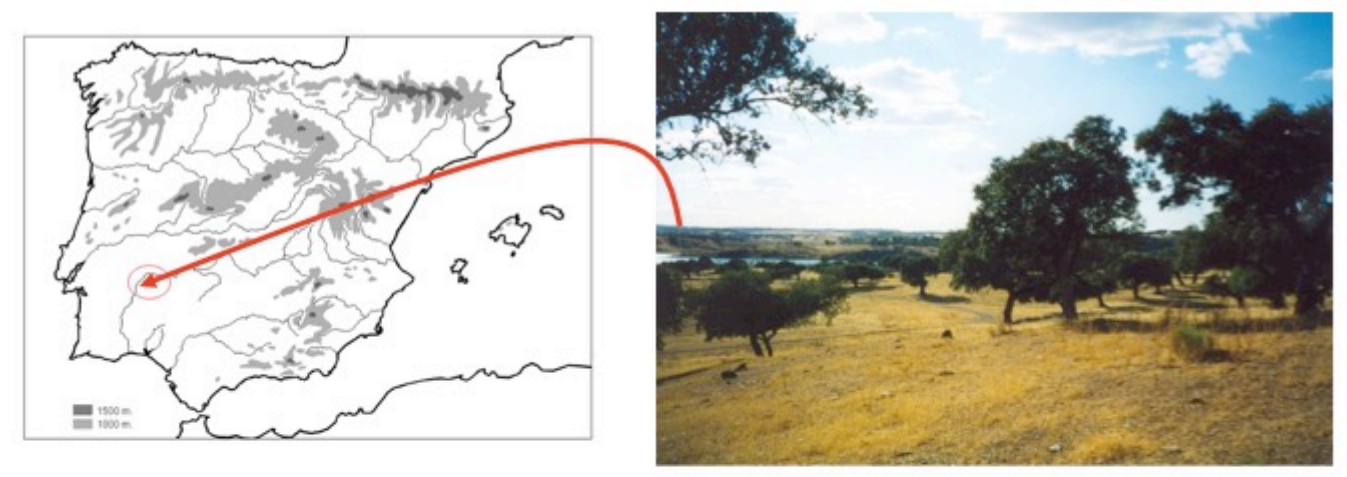

\begin{tabular}{|l|c|c|}
\hline \multicolumn{1}{|c|}{ Period } & $\begin{array}{c}\text { Uncalibrated } \\
\text { Dates } \\
\text { (in bc) }\end{array}$ & $\begin{array}{c}\text { Calibrated } \\
\text { Dates } \\
\text { (in BC) }\end{array}$ \\
\hline Early Copper Age & $2800-2300$ & $3500-2800$ \\
\hline Middle Copper Age & $2300-2000$ & $2800-2400$ \\
\hline $\begin{array}{l}\text { Bell Beaker Copper } \\
\text { Age }\end{array}$ & $2000-1800$ & $2400-2200$ \\
\hline $\begin{array}{l}\text { Bronze Age } \\
\text { Transition }\end{array}$ & $1700-1100$ & $2000-1300$ \\
\hline
\end{tabular}

Fig 1
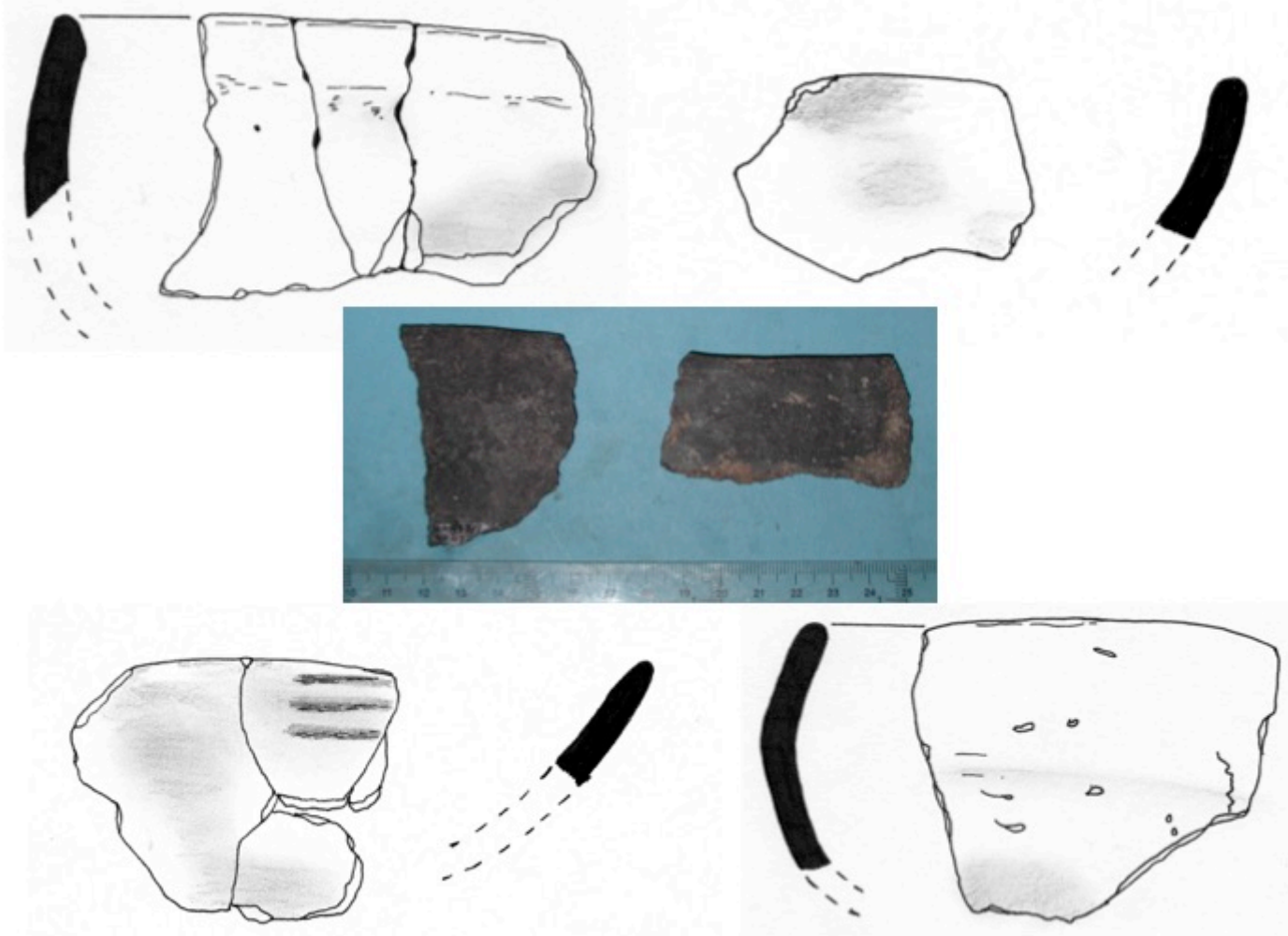

Fig 2 


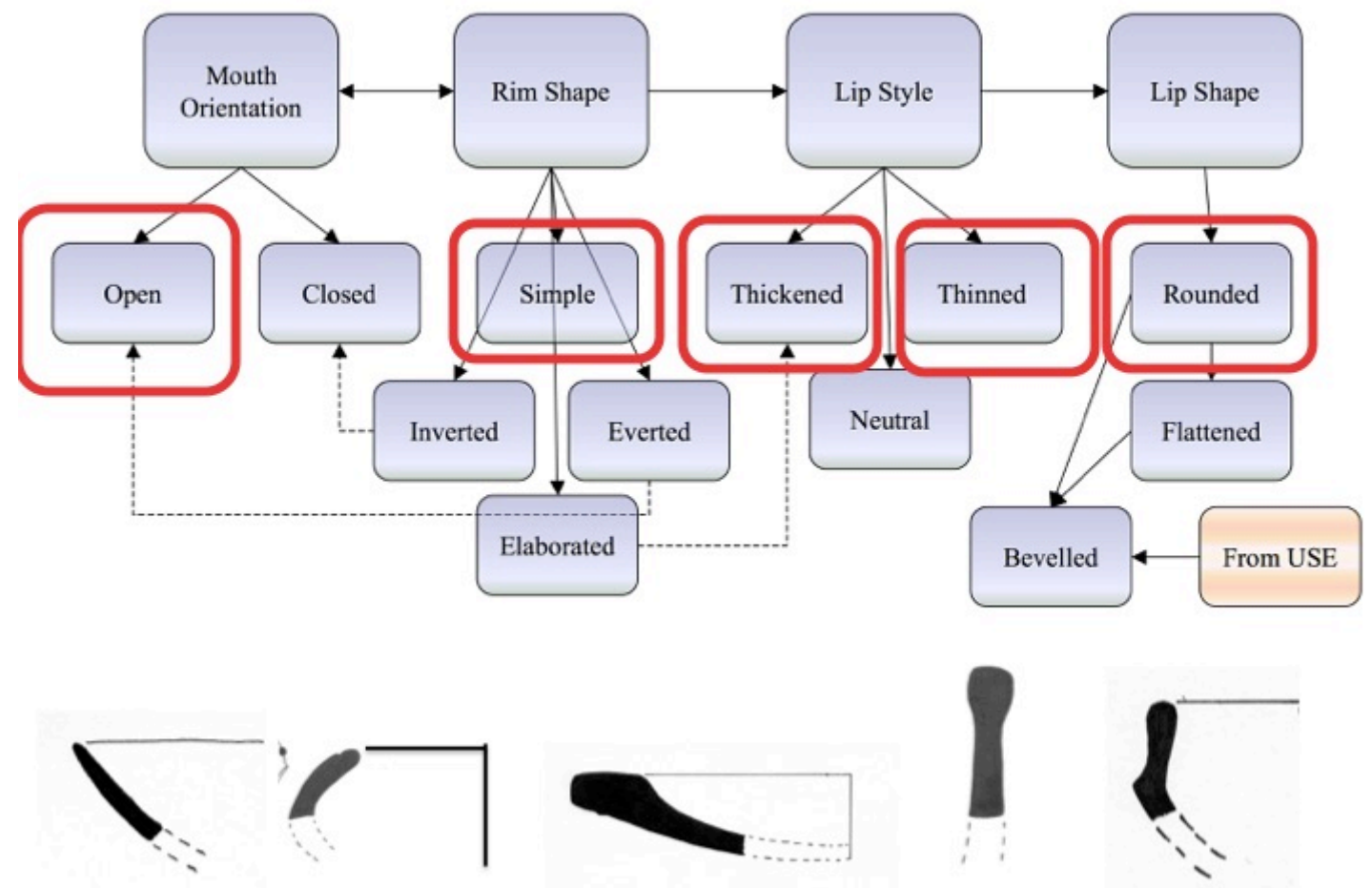

Fig 3

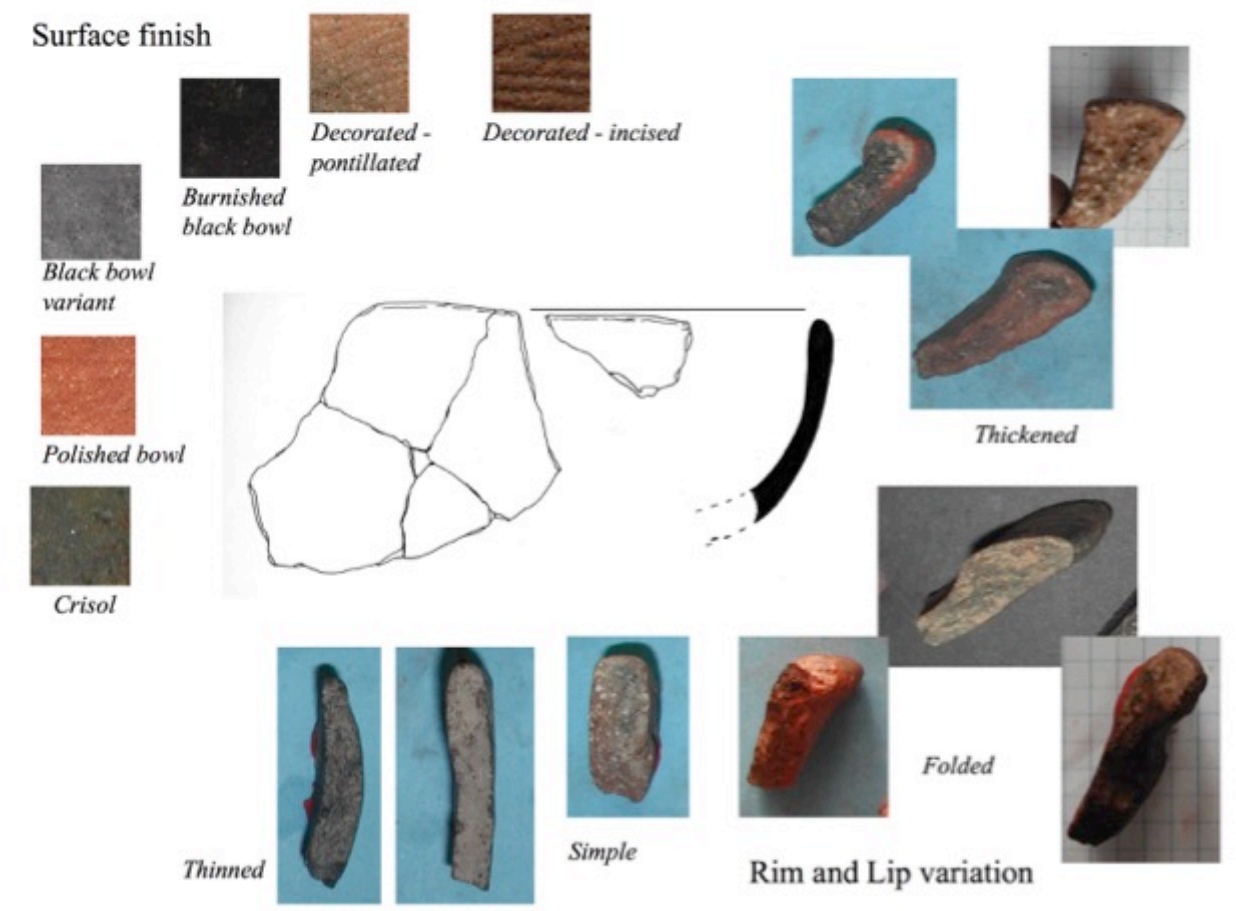

Fig 4 

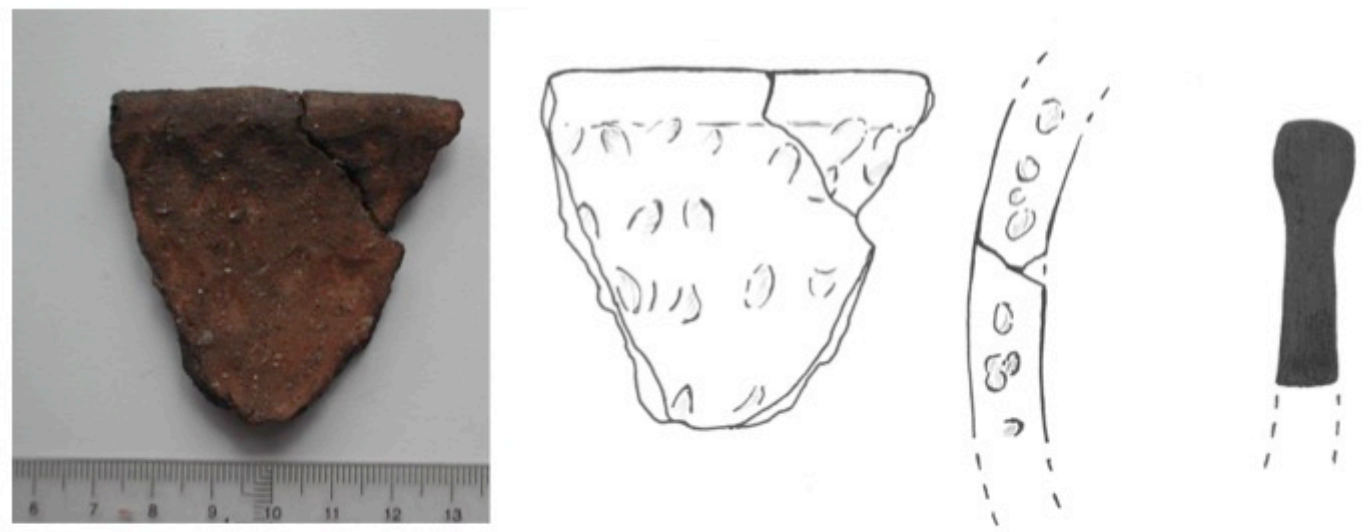

Fig 5
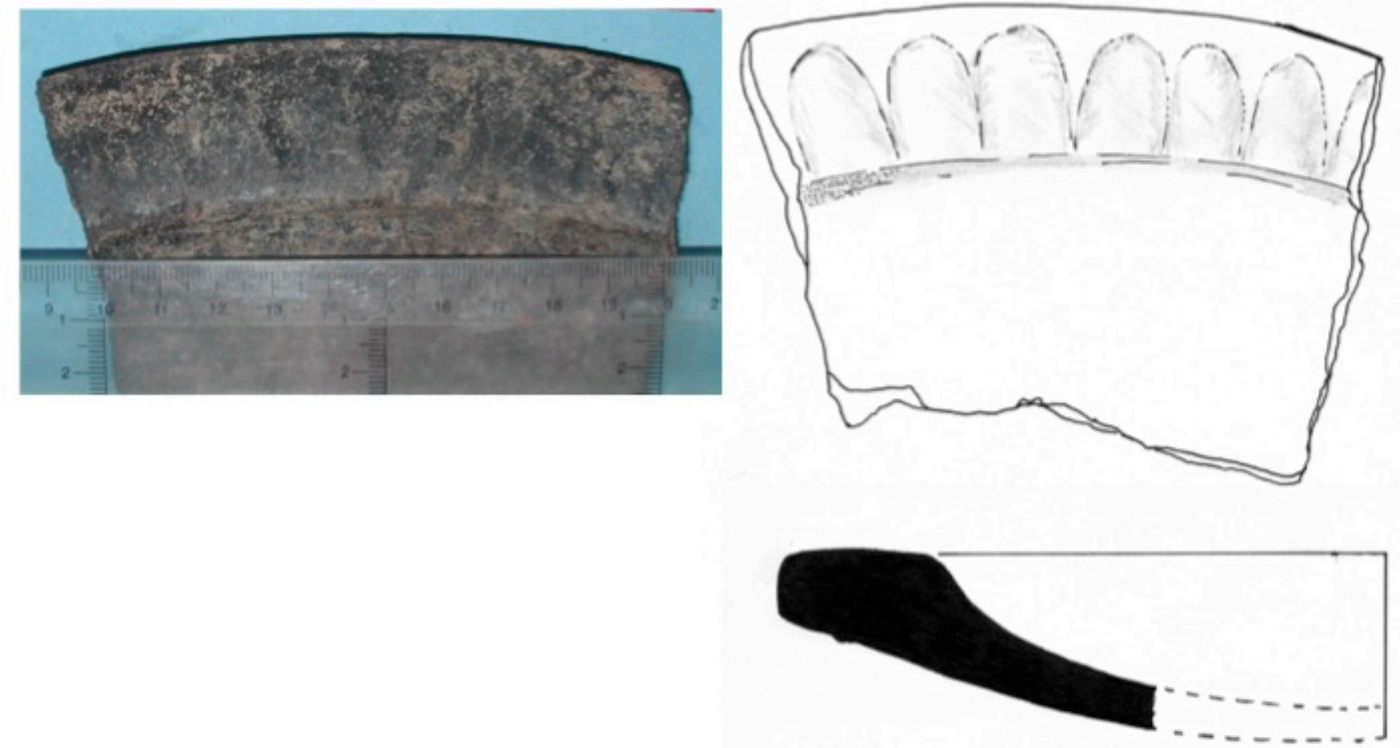

Fig 6 